\title{
Deterritorialising to Reterritorialising the Curriculum Discourse in African Higher Education in the Era of the Fourth Industrial Revolution
}

\author{
Kehdinga George Fomunyam ${ }^{1}$ \\ ${ }^{1}$ Teaching and Learning Development Center, Mangosuthu University of Technology, South Africa \\ Correspondence: Kehdinga George Fomunyam, Teaching and Learning Development Center, Mangosuthu \\ University of Technology, South Africa
}

Received: April 2, 2020

Accepted: May 5, 2020

Online Published: May 12, 2020

doi:10.5430/ijhe.v9n4p27

URL: https://doi.org/10.5430/ijhe.v9n4p27

\begin{abstract}
The Fourth Industrial Revolution is upon us, and it comes with implications for the higher education curriculum and organisations within Africa. Technology that was ubiquitous in previous decades, is now becoming obsolete. Artificial intelligence and digitization, which are features of the Fourth Industrial Revolution, are now the order of the day. Organisations are moving with such technological advancement by adopting newly created technologies of the Fourth Industrial Revolution. Without doubt, the currently used curriculum in Africa is obsolete; and does not capture the changes being ushered in by the Fourth Industrial Revolution. Therefore, the higher education curriculum must be responsive to the Fourth Industrial Revolution, as this will prepare students in Africa for the challenge ahead. This study theorises on, and has concluded, that deterritorialization and reterritorialization are useful in making the African higher education responsive to the curriculum. The study recommends the introduction of Science, Technology, Engineering, and Mathematics (STEM) education into the African higher-education curriculum in Africa. STEM will produce students who are technically savvy, helping students in Africa to acquire the needed skills to perform seamlessly in organisations operating within the Fourth Industrial Revolution era.
\end{abstract}

Keywords: deterritorialising, reterritorialising, curriculum responsiveness, African higher education

\section{Introduction}

The Fourth Industrial Revolution (4IR) is outgrowing and outliving the Third Industrial Revolution, and it has implications for higher education in Africa. The 4IR is the current and developing environment in which disruptive technologies and trends are changing the way we live and work (Rouse, 2017). 4IR comes with high digitization. Some of the features of the 4IR include mobile supercomputing, intelligent robots, self-driving cars, neuro-technological brain enhancements, and genetic editing. Higher education in Africa is in danger of being left behind, if serious consideration is not given to the 4IR, and the digitization that it comes with.

Because of the 4IR, traditional methods of employment and organisational processes are being challenged by the digitalization of the workplace. This explains Gwata's (2019) argument that, in certain industries, as a result of the $4 I R$, the labour force is being eroded through recent technologies. The exact impacts of 4IR technologies on society and the planet are still unknown. However, what is certain is that they will bring profound and rapid change to all facets of human life, including education. Penprase (2018) asserts that the 4IR will shape the future of education and will require accelerated workforce reskilling. In some years from now, artificial intelligence, which is a feature of the 4IR, will continue to penetrate every major industry, be it marketing, hospitality, mining, advertising, transportation, the law, and education. Almost every, if not every workplace and every job will be affected in some way. This will impact on the society whether positively or negatively; and these impacts and changes have not yet been captured in the African higher-education curriculum.

The current curriculum used in African higher education is old, and mostly irrelevant to the demands of the 4IR. Most of the contents of the curriculum cannot equip students with necessary skills to perform in organisations of the future. For this reason, Iruonagbe and Egharevba (2015) comment that the curriculum used in African higher education does not allow students to be properly trained; therefore, they lack the necessary skills to fit into automated organisational settings. Similarly, Mba (2017) acknowledges that the current content of the curriculum used by African higher education does not match the current labour market demand and/or development needs. There is 
therefore a dissonance between the curriculum of the African higher education and the demands of employers in the 4IR.

A reconfiguration of higher education in Africa is needed for it to become responsive to the 4IR. This will play a critical role in allowing individuals to build successful careers and businesses that are augmented and not threatened by these new technologies (Gwata, 2019). Similarly, Penprase (2018) is of the view that substantial changes to the educational curriculum will be required to allow for students to develop capacity in the rapidly emerging areas of genomics, data science, AI, robotics, and nanomaterials. Higher education in Africa must inculcate digitization of the $4 \mathrm{IR}$, to ensure that employees are knowledgeable on the use of newly developed organisational technologies. It is important that this be accomplished, because the current curriculum used in Africa may not be fit for purpose. Therefore, educators and policymakers in Africa have a responsibility to prepare students, providing them with the knowledge and understanding of pertinent technologies, and also the skills that allow students to become successful employees and employers in the 4IR period. How can this feat be achieved in Africa?

Reterritorialising the African higher-education curriculum may be an effective strategy in obliging higher education in Africa to become responsive to the 4IR currently being witnessed. According to definitions.net, reterritorialization is the restructuring of a place or territory that has experienced deterritorialization. Therefore, reterritorialization and deterritorialization are closely related. That is to say, for African higher education to be reterritorialised, it has first to be deterritorialised, and to deterritorialise means to undo what has been done. Therefore, in the educational context, to achieve reterritorialization and hence curriculum responsiveness to the 4IR in Africa, the curriculum being presently used in Africa must be deterritorialised. This study will assess how higher education in Africa can be deterritorialised to make certain that the curriculum is responsive to the digitization of the 4IR.

This study is divided into four parts. The first part centres on explaining deterritorialization and reterritorialization, the Fourth Industrial Revolution, and curriculum responsiveness. The second section focuses on explaining how deterritorialization and reterritorialization can be used to achieve curriculum responsiveness to the Fourth Industrial era. The last part of the paper concludes the study; recommendations are made, and the contribution of the paper to knowledge is defined.

\section{Concept of Deterritorialization and Reterritorialization}

The terms deterritorialization and reterritorialization are used to characterise a constant process of transformation (Aurelea, 2008). Deterritorialization is the eradication of social, political, or cultural practices from their native places and populations. African higher education is influenced by an array of concepts, expectations, and actions. When the African higher-education curriculum is deterritorialised, these concepts, expectations, and actions are totally discarded. Therefore, deterritorialization may mean to take charge of the African higher-education curriculum by sensitising Africans on the need to change the curriculum and mapping out strategies to ensure a successful change to the curriculum. Simply put, deterritorialization, in the context of this study, means to undo what has been achieved in the African curriculum.

There have been a number of examples of past events that explain what is meant by deterritorialization in terms of territories. For example, when the Spanish conquered the Aztecs, the Spanish eliminated many symbols of Aztec beliefs and rituals. In times past, when a territory was conquered, the conquerors always make sure that they deterritorialised the territory. Deterritorialization of conquered territories could be in the form of destroying important symbols of the conquered territory, while religious beliefs have sometimes been eroded. In Africa, after the colonial masters invaded the continent, they sought to deterritorialise the continent. They came with their own religious beliefs, symbols, rituals, and mode of dress (Frankema, 2015).

Deterritorialization is always accompanied by reterritorialization. Reterritorialization, in the context of this study, means the restructuring of the African higher-education curriculum that has been deterritorialised. Aurelea (2008) asserts that reterritorialization is the process of redoing what has been undone, making it over anew. Similarly, Deleuze (n.d.) explained that reterritorialization is the establishment of a new relationship, a new process, a new interaction, a new interlinking, providing a new concept, redefining, reconfiguring, and recombining practices. To reterritorialise the African higher-education curriculum in this era is to include contents that are relevant to the 4IR, and which will ensure that students in Africa have the necessary skills and capacities to operate efficiently in the future organisations. In essence, deterritorialization means to undo what has been existing, while reterritorialization means to re-do what has been undone in a specific, clear, and unique manner, different from what was in place before deterritorialization took place. 
In summary, deterritorialization in education refers to an action that promotes disorder, reflection, review, fragmentation of principles, rebuilding, defragmenting again, but using new shades, aspects, and characteristics (Barone, Zaro, \& Musacchio, 2015). Therefore, to deterritorialise education in Africa is to abolish the curriculum handed over to Africans by their colonial masters. By abolishing such, this means to stop using the current educational curricula being used in Africa. Reterritorialization can be achieved by compiling new curricula specific to the African continent. This is significant in fostering the educational curriculum in Africa to become territory-specific, and to become responsive to the Fourth Industrial Revolution.

\section{The Fourth Industrial Revolution (4IR)}

Before the Fourth Industrial Revolution, there were the First, the Second, and the Third Industrial Revolutions. The 1IR fell largely into the period 1760 to 1830 . Britain was regarded as the major protagonist. The revolution arose once iron, coal, and textiles could be mined or produced for the general populace. According to Duignan (n.d.), Britain was aware of her leadership in technology. Britain therefore forbade the export of machinery, skilled workers, and manufacturing techniques. However, this could not last long, as some Britons exported their knowledge for financial gain. The main features of the 1IR were the transcontinental railroad, the cotton gin, electricity, and other inventions. These inventions permanently changed the human race. The 2IR is also known as the technological revolution (Muntone, 2013). The 2IR was a phase of rapid industrialization from 1870-1914. The First Industrial Revolution caused the growth of industries, such as coal, iron, railroads, and textiles, while the Second Industrial Revolution witnessed the expansion of electricity, petroleum, and steel (Study.com, n.d.). The 2IR provided great advancements in technology, steel production, petroleum, and electricity, and these led to the production of automobiles and aeroplanes. The 3IR is also known as the digital revolution. It began in the 1950s. This revolution brought us semiconductors, mainframe computing, personal computing, and the Internet - the digital revolution (Trailhead.com). Things that used to be analogue became digital in the 3IR. Most of the technology we have nowadays is digital. Laptops, phones, and tablets now use the Internet, representing a sharp move from analogue technology to digital technology. Modern 3D printing, otherwise known as additive manufacturing, is another major feature of the 3IR.

However, even with the advancement in technology in the 3IR, the world is now tilting towards the Fourth Industrial Revolution, and this is happening before our very eyes. Digitization is now on a new level never before comprehended. One of the main features of the Fourth Industrial Revolution is the use of robotics and artificial intelligence in almost every aspect of life. The Fourth Industrial Revolution currently making waves will no doubt make living easier and more exciting. The Fourth Industrial Revolution (4IR) refers to how technologies such as artificial intelligence, autonomous vehicles, and the Internet of things are merging with humans' physical lives (Schulze, 2019). Some of the features of the 4IR include voice-activated assistants; facial ID recognition; and digital health-care sensors. According to the World Economic Forum [WEF] (2019), the 4IR represents a fundamental change in the way we live, work, and relate to one another, because this is a new chapter in human development, enabled by extraordinary technology advances commensurate with those of the first, second and third industrial revolutions. The WEF goes further by asserting that the 4IR is about more than simply technology-driven change; it is an opportunity to help everyone, including leaders, policymakers and people from all income groups and nations to harness converging technologies in order to create an inclusive, human-centred future. This means that 4IR is not only technology-driven, but centres on improving life for the world's population.

The 4IR is already reshaping industries today. This is because organisations today have access to high-speed Internet, constantly improving their artificial intelligence, and adopting big-data analytics and cloud technology (Buis, n.d.). These are all features of the 4IR. Some other features of the 4IR are artificial intelligence; robotics; IOT; quantum computing; virtual reality (VR); augmented reality (AR); unmanned aerial vehicle (UAVs); 3D printing; and block chain technology. Artificial intelligence is another major feature of the 4IR. The advancement of technology has led to an increased role played by artificial intelligence in today's world. Artificial intelligence is the development of technology to replicate and improve upon human intelligence (Kambria, n.d.). According to Kambria (n.d.), artificial intelligence can be classified into three sub-categories: artificial narrow intelligence (AI that can perform a single simple task, such as voice recognition); artificial general intelligence (AI that can perform multiple tasks across a number of different areas); and artificial super intelligence (AI that has the ability to produce 'intelligence' beyond that of human capability). All of these categories put together will make life easier, more enjoyable and more productive, making the 4IR an era bursting with possibilities. As exciting as the 4IR already sounds, it is only just emerging; we are still in the first phase of the 4IR. 
Although all industrial revolutions from the first to the fourth have some commonality, they also have large differences. As stated, all of the inventions in each of the industrial revolutions changed society on a fundamental and economic scale (Finley-Moise, 2019). The major difference between the earlier IRs and this one is that the 4IR aspires to merge physical, digital, and biological spheres to foster an inclusive, human-centred future. Finley-Moise (2019) stated that the 4IR looks beyond pure technological advances and concentrates on innovative methods of accomplishing the greatest good for the greatest number of people, communities, and organisations.

Organisations and corporate leaders have been busy tweaking their business processes to meet the changing demands of the 4IR. The educational sector may not be doing enough to prepare students to step into a new world in which robotics, automation, and big-data analytics are taking centre stage. The Organisation for Economic Cooperation and Development (OECD) estimates that, over the next 10 to 20 years, 14 per cent of jobs are at high risk of being fully automated; while another 32 per cent are at risk of significant change (Study International Staff, 2019). This makes it important for education to prepare and equip students to meet the dynamic demands of the anticipated automated workplace. However, Study International Staff (2019) have argued that education has been slow to adapt to rapid technological advancements, students therefore being ill-prepared for the world they will soon inherit.

The 4IR comes with exciting possibilities, new solutions to global challenges, and employment opportunities that have yet to be invented. At the same time, it comes with the potential for technological unemployment that drives downward pressure on income security and social agency, while society adapts to the new normal (Brown-Martin, 2018). That is to say, even though the 4IR promises exciting times, it could be dead on arrival if there are no capable hands to operate the technologies being developed. The onus therefore falls on governments and educators to rethink education and how to prepare the next generation to take advantage of the plethora of opportunities ahead. The youth must overcome the challenges wrought by ever-increasing technological change (Marr, 2019).

The 4IR has profound implications for higher education in Africa, which needs urgent attention. Education in Africa must become responsive to the 4IR to ensure that students are well prepared and equipped to thrive in the future workplace. As suggested earlier, deterritorialization to achieve reterritorialization may be useful in higher education in Africa responding to the 4IR.

\section{Curriculum Responsiveness}

Curriculum responsiveness is the ability of curricula taught in schools or universities to address student needs as well as societal circumstances (Moll, 2004). This means that, for a curriculum to achieve responsiveness, it has go beyond simply meeting the needs of students. Also, it has to consider the effects it will have on the well-being of society in general. In the context of this study, curriculum responsiveness implies the ability of the African curriculum to become responsive to the demands of the Fourth Industrial Revolution. The 4IR is, as yet, in its infant stages. However, in no distant time, the workplace will demand employees who are tech savvy. This makes it imperative that the African curriculum respond to the changes, in preparation for what lies ahead for students in Africa. For African higher education to achieve full responsiveness, it has to become economically, culturally, disciplinarily, and learning responsive.

Economic responsiveness to a curriculum is concerned with the ability of a curriculum to train skilled and capable professionals in the various sectors of the economy (Fomunyam \& Teferra, 2017). Thus, a curriculum is economically responsive to this era when the curriculum has the ability to produce graduates able to cope with the digitization of the organisational workspace. An economically responsive curriculum will groom students that have the skills and know-how to create, develop, and nurture long-lasting solutions to organisational problems in this era of globalisation. An economically responsive curriculum will therefore produce students that will find solutions not to only current organisational problems, but also to future organisational problems. The 4IR will comprise organisations preferring tech-savvy graduates to non-tech-savvy graduates. The workplace will soon become automated, as a result of the technologies being invented in the 4IR. Organisations in Africa will only have access to tech-savvy graduates if the curriculum in Africa becomes economically responsive. On the other hand, it is necessary that the curriculum in African higher education become culturally responsive. According to Moll (2004), a culturally responsive curriculum is the ability of the curriculum to access and respond to the cultural dissonance in the classroom - a classroom supposedly divided in terms of race, ethnicity, religion, age and gender. A culturally relevant curriculum is concerned with teachers displaying cultural competence. Teachers must have skill in teaching within a cross-cultural or multi-cultural setting. A culturally responsive curriculum will encourage students to relate course contents to their own cultural context. Deady (2017) relates that culturally responsive teaching goes beyond merely recognising the cultural background of students. It is inclusive of adaptive teaching, and teaching students to recognise and embrace diversity. Deady (2017) further posits that the classroom will become increasingly culturally 
divided. This will be as a result of globalisation and internalization in the era of the 4IR, calling for responsiveness of the curriculum in terms of culture with respect to the African higher education.

Disciplinarily responsiveness to the African higher-education curriculum is equally important. Ferdinand (2009) asserted that disciplinarily responsiveness to the African higher education is the ability of the curriculum to be up to date with the research in the field, while promoting new discoveries within the discipline. The African higher-education curriculum must be continually updated to include new thoughts and knowledge in various disciplines. Research is conducted from time to time by researchers and scholars in all disciplines in higher education. These researches always allow for new knowledge that was previously unknown. Not updating the curriculum to include such new knowledge will cause curriculum obsolescence, not following with trend, globally. The African higher education curriculum must become disciplinarily responsive: graduates from Africa must have up-to-date knowledge of their respective disciplines. This will maintain relevance in current organisational settings. It will also make new employees useful in the future workplace. Moja (2004) asserted that disciplinarily responsiveness of the African higher-education curriculum will ensure that what is happening locally and internationally, as far as any discipline is concerned, is included in the curriculum. Such will provide students in Africa with necessary skills suited to solving current and anticipated organisational problems.

Finally, the African higher-education curriculum, in achieving full responsiveness, must be learning responsive. Learning responsiveness, for a curriculum, according to Fomunyam and Teferra (2017) is the curriculum's ability to respond to the needs of the student. Students in a classroom have needs that should not be left unattended to by teachers. The risk is that students become bored and may not be willing to learn. Therefore, a curriculum must take into serious consideration the needs of individual students, making sure that these needs are not left unmet.

The most important question to ask now is: how can the curriculum in Africa achieve responsiveness to the era of the Fourth Industrial Revolution? A number of solutions have been proposed by various authors, scholars, and researchers in the literature. However, this study proposes a solution unique to the ones already studied in the literature. This study proposes deterritorialization to achieve reterritorialization as factors useful in making the African curriculum responsive to the challenges and demands of the Fourth Industrial Revolution.

\section{Curriculum Responsiveness in the Era of the Fourth Industrial Revolution}

This section is used to outline methods that can be used to ensure that the African educational curriculum becomes responsive to the Fourth Industrial Revolution. The curriculum, first of all, must discard its current contents, as they have become obsolete and archaic. After this has been achieved, reterritorialization can be achieved by inputting contents into the curriculum that will be useful and necessary to prepare the minds of students for the Fourth Industrial Revolution when eventually it comes into full play. The curriculum used in Africa is the curriculum which remained when the colonial masters left the continent. This curriculum has now become obsolete in Africa. Why should the curriculum need to be deterritorialised to meet the demands of today's world? Africa cannot continue to use the curriculum that has been in existence for over seventy years. This is not sustainable, and it does not bode well for education in Africa. If the curriculum is not deterritorialised, Africa will simply be producing second-grade graduates that will not have major significance in the labour market. Further, if the curriculum is not deterritorialised, Africa will have to import expatriates from all over the world to help operate machines purchased by the country.

Deterritorialising the curriculum is not something that is extremely difficult to do. What is essential is that the sections of the current curriculum not useful in the Fourth Industrial Revolution be deleted. All educational fields have this problem. Some content was already obsolete in the Third Industrial Revolution, let alone in the Fourth Industrial Revolution. For example, in Business Studies, students are still taught about typewriters, long since obsolete. Topics covering typewriting in business studies should be abolished from the curriculum. This will provide space for more relevant content to be included in the curriculum. Briggs (2016) argues that, within the next ten years, we will start to see less of Biology, Math, English, and more of Big Data, Creative Studies, and Decision Sciences. All this must be taken into consideration when deterritorialising the African curriculum. If something is not done swiftly, the conventional universities will all become obsolete. This sums up the argument that the African curriculum is filled with outdated courses and course content that must be abandoned and replaced by newer content that meets the demands of the Fourth Industrial Revolution. After deterritorialization is achieved, how do we reterritorialise?

One crucial method of reterritorialising or redirecting education in Africa in the Fourth Industrial Revolution is to introduce Science, Technology, Engineering, and Mathematics (STEM) education to students of higher education in Africa. STEM is curriculum-based, buying into the idea of educating students in four specific disciplines - science, technology, engineering, and mathematics - per an interdisciplinary and applied approach (Hom, 2014). This means 
that, in STEM education, these four disciplines will not be taught as separate or discreet subjects. They will be integrated into a cohesive learning paradigm based on real-world applications (Hom, 2014). It is important that STEM be introduced into African higher education, because, in the Fourth Industrial Revolution, scientific and technological innovations will become increasingly important as we face the benefits and challenges of both globalisation and a knowledge-based economy (engineeringforkids.com, 2019). Therefore, to succeed in this new information-based and highly technological society, students must develop their capabilities for STEM subjects to levels far beyond what was considered acceptable in the past.

STEM education comes with some major objectives that perfectly suit the Fourth Industrial Revolution. Lynch (2019) posits that STEM education fosters ingenuity and creativity. The recent developments in artificial intelligence and digital learning arose as a result of ingenuity and creativity. Therefore, to successfully operate these innovations, ingenuity and creativity is needed. These skills are exactly what STEM develops in its students. According to Lynch (2019), STEM encourages students to experiment. This is a vital skill for the Fourth Industrial Revolution. Experimenting is a major part of the Fourth Industrial Revolution. Thus, it is pertinent that African graduate students be experimental, as this will make innovations possible in Africa. Africa must not be obliged to buy innovations but must also invent new technologies in their own backyard.

STEM encourages teamwork. Lynch (2019) stated that STEM education can be taught to students of all levels of ability. Such students must be able to work together in teams to find solutions to problems, recording data, writing reports and giving presentations. Most innovations are achievable as a result of teamwork, which the pursuit of STEM ensures. In addition, STEM, if integrated into the African higher-education curriculum, will encourage students' knowledge application, encouraging tech usage, teaching problem-solving, and encouraging adaptation. It is important that students in Africa possess all of these skills, thus being prepared for the demands of future organisations. STEM students are taught essential skills needed for the Fourth Industrial Revolution. Thus, when they enter the workforce, they can apply the knowledge they learnt in school to accomplish organisational tasks.

STEM belongs to the modern classroom and is essential for use in the Fourth Industrial Revolution. STEM lessons address real social, economic, and environmental problems, and encourage solutions to them. STEM lessons are guided by the engineering design process; they immerse students in hands-on inquiry and open-ended exploration; and they apply rigorous math and science content which students are learning (Watanabe-Crockett, 2019). Such skills will equip students in Africa to operate seamlessly within organisations of the Fourth Industrial Revolution.

STEM education in Africa still leaves a lot to be desired. Africa has not embraced STEM wholeheartedly. Most African schools still do not have STEM as part of their curriculum. Most governments in Africa still do not know what STEM is, the concomitant benefits, and how important it is to prepare African students for the technological innovations in the Fourth Industrial Revolution. The curriculum in Africa should be developed in such a way that it will instil in students a love for continuous learning (Study International Staff, 2019). The Fourth Industrial Revolution is a tech-driven era. Continuous learning and upskilling must be applied to meet the ever-changing needs of the workforce. Therefore, the African curriculum must develop learning skills in students. It is essential for students of the Fourth Industrial Revolution to continually develop themselves for the constant technological innovations that are a major feature of the Fourth Industrial Revolution.

Earlier, it was stated that the curriculum in Africa must become economically, culturally, disciplinarily, and learning responsive to the 4IR. The STEM education is a composite answer to this. First, STEM education will provide students with necessary technical abilities to solve anticipated organisational problems. Second, STEM education favours collaborative learning in class. This will foster students working with students from other cultural backgrounds, mostly on a daily basis. As a result, students will become comfortable working with anyone, no matter their cultural background. Hence, cultural responsiveness will be achieved. Third, STEM education is disciplinarily responsive, because, what will be taught to students is newly invented content that suits the organisational 4IR workplace. Finally, STEM education is an interesting field of study. Students should always be interested in class lessons. The contents of STEM education favour more technology and science, which interests most students of today. With this, learning responsiveness is also achieved.

\section{Conclusion and Recommendation}

The Fourth Industrial Revolution is already upon us. We have been witnessing in recent years mind-blowing technological innovations, such as 3D printing, 5G networks, robotics, and artificial intelligence. These advancements in technology have changed and will continue to massively change organisational processes. There are now technological inventions for organisations that will alter their mode of activities. Students without the 
know-how of these technological advancements will be unable to become successful employees. For this reason, education in Africa has to be responsive to the Fourth Industrial Revolution.

This study assessed how deterritorialising the African higher-education curriculum can promote the curriculum's responsiveness to the Fourth Industrial Revolution. Deterritorialising the African curriculum will involve undoing the current curriculum in Africa, then reworking the curriculum by reterritorializing it to become responsive to the needs of students in the Fourth Industrial Revolution. This study, based on its findings, concludes that deterritorialising to reterritorialising African higher education will ensure that the curriculum achieves responsiveness to the Fourth Industrial Revolution.

This study therefore recommends that, to achieve curriculum responsiveness in the era of the Fourth Industrial Revolution, the higher-education curriculum first be deterritorialised. It must then be reterritorialised by introducing STEM education into the African curriculum. STEM education will provide students with needed skills for the Fourth Industrial Revolution. Again, the curriculum should encourage personal learning and development. Personal learning and development is essential in today's era of technological advancement.

\section{References}

Aurelea (2008). Deterritorialization and reterritorialization. Retrieved from https://culturenet.wordpress.com/2008/03/06/deterritorialization-and-reterritorialization/ [Accessed on 31/10/19].

Barone, D. A. C., Zaro, M. A. \& Musacchio, C. D. (2015). Delocalization and spatialization of the classroom: Deterritorialization in education. American Journal of Educational Research, 3(11), 1417-1428. https://doi.org/10.12691/education-3-11-11

Briggs, S. (2016). 12 facets of education that will be obsolete by 2025. Retrieved from https://www.opencolleges.edu.au/informed/features/25-things-that-will-be-obsolete-by-2025/ [Accessed on 31/10/19].

Brown-Martin, G. (2018). Education and the Fourth Industrial Revolution. Retrieved from https://medium.com/learning-re-imagined/education-and-the-fourth-industrial-revolution-cd6bcd7256a3/ [Accessed on 10/31/19]. https://doi.org/10.21125/iceri.2018.2771

Deady, K. (2017). 5 steps to becoming a culturally responsive teacher. Retrieved from www.teachaway.com/ [Accessed on 19/11/19].

Duignan, B. (2017). Industrial revolution. Retrieved from https://www.britannica.com/event/Industrial-Revolution\#ref3502/ [Accessed on 10/29/19].

Engineeringforkids.com (2019). Why is STEM so important? Retrieved from https://www.engineeringforkids.com/about/news/2016/february/why-is-stem-education-so-important-/

Ferdinand, D. S. (2009). Workforce education and development curriculum responsiveness to culturally and internationally diverse graduate students: A mixed methods study. Carbondale: Carbondale Southern Illinois University.

Finley-Moise, T. (2019). Where the Fourth Industrial Revolution is Taking Us. Retrieved from https://store.hp.com/app/tech-takes/where-fourth-industrial-revolution-is-taking-us/ [Accessed on 10/31/19].

Fomunyam, K. G. \& Teferra, D. (2017). Curriculum responsiveness within the context of decolonisation in South African higher education. Perspectives in Education, 35(2), 196-207.DOI: http://dx.doi.org/10.18820/2519593X/pie.V35i2.15

Frankema, E. (2015). How Africa's colonial history affects its development. Retrieved from https://www.weforum.org/agenda/2015/07/how-africas-colonial-history-affects-its-development/ [Accessed on 13/10/19].

Gwata, M. (2019). To flourish in the Fourth Industrial Revolution, we need to rethink these 3 things. Retrieved from https://www.weforum.org/agenda/2019/08/fourth-industrial-revolution-education/ [Accessed on 10/29/19].

Hom, E. J. (2014). What is STEM Education? Retrieved from https://www.livescience.com/43296-what-is-stem-education.html/ [Accessed on 31/10/19].

Iruonagbe, C. T. \& Egharevba, M. E. (2015). Higher education in Nigeria and the emergence of private Universities. International Journal of Education and Research, 3(2), 49-64. 
Kambria (2019). The Role of AI and Robotics in the Fourth Industrial Revolution. Retrieved from https://medium.com/kambria-network/the-role-of-ai-and-robotics-in-the-fourth-industrial-revolution-81a749f66 740/ [Accessed on 12/11/19].

Lynch, M. (2019). 7 benefits of STEM education. Retrieved from https://www.theedadvocate.org/7-benefits-of-stem-education/ [Accessed on 31/10/19].

Marr, B. (2019). 8 things every school must do to prepare for the 4th industrial revolution. Retrieved from https:/www.forbes.com/sites/bernardmarr/2019/05/22/8-things-every-school-must-do-to-prepare-for-the-4th-in dustrial-revolution/\#72354700670c/ [Accessed on 10/31/19].

Mba, J. C. (2017). Challenges and prospects of Africa's higher education. Retrieved from https://www.globalpartnership.org/blog/challenges-and-prospects-africas-higher-education/ [Accessed on $12 / 11 / 19]$.

Moja, T. (2004). Globalisation: A challenge for curriculum responsiveness. In H. Griesel (Ed.). Curriculum responsiveness: Case studies in higher education (pp. 21-38). Pretoria: South African Universities Vice-Chancellors Association.

Moll, I. (2004). Curriculum responsiveness: The anatomy of a concept. In H. Griesel (Ed.). Curriculum responsiveness: Case studies in higher education (pp. 1-19). Pretoria: South African Universities Vice-Chancellors Association

Muntone, S. (2013). Second industrial revolution. London: McGraw-Hill Companies.

Penprase, B. E. (2018). The Fourth Industrial Revolution and higher education. Higher Education in the Era of the Fourth Industrial Revolution, 207-229. https://doi.org/10.1016/j.nbt.2017.04.004.

Rouse, M. (2017). Fourth Industrial Revolution. Retrieved from https://whatis.techtarget.com/definition/fourth-industrial-revolution/ [Accessed on 10/29/19].

Schulze, E. (2019). Everything you need to know about the Fourth Industrial Revolution. Retrieved from https://www.cnbc.com/2019/01/16/fourth-industrial-revolution-explained-davos-2019.html/ [Accessed on $10 / 31]$

Study.com (n.d.). The second industrial revolution: Timeline \& inventions video. Retrieved from https://study.com/academy/lesson/the-second-industrial-revolution-timeline-inventions.html/ [Accessed on $10 / 29 / 19]$.

Study International Staff (2019). How can schools prepare students for the Fourth Industrial Revolution? Retrieved from https://www.studyinternational.com/news/how-can-schools-prepare-students-for-the-fourth-industrial-revolutio n/ [Accessed on 10/31/19].

Watanabe-crockett, L. (2019). 6 reasons why stem learning belongs in the modern classroom. Retrieved from https://www.wabisabilearning.com/blog/stem-learning-modern-classroom/ [Accessed on 31/10/19].

World Economic Forum (2019). Fourth Industrial Revolution. Retrieved from https://www.weforum.org/focus/fourth-industrial-revolution/ [Accessed on 10/31/19]. 